\title{
Uptake of health checks by residents from the Danish social housing sector $-a$ register-based cross-sectional study of patient characteristics in the 'Your Life - Your Health' program
}

\author{
Lars Bruun Larsen ${ }^{1 *}$, Annelli Sandbaek ${ }^{2,3}$, Janus Laust Thomsen ${ }^{4}$ and Anne-Louise Bjerregaard ${ }^{2}$
}

\begin{abstract}
Background: Poor uptake among socio-economically disadvantaged and susceptible populations is a well-known challenge of general health check interventions, and is widely cited as one of the reasons for the lack of population level effects seen in many studies. We report on patient characteristics among attendees and non-attendees of health checks made available to residents in the social housing sector of the municipality of Aarhus. We focus on this general population, as well as a particular sub-group living in an exceptionally deprived social housing area, and discuss the properties of intervention uptake that we need to be aware of to qualify and compare the effects of general versus targeted health checks in socially deprived areas.

Methods: Cross-sectionally in a sample of 6650 residents of the Aarhus social housing sector who were invited for a health check in the first year of the 'Your Life - Your Health' program. The analyses consisted of 1) descriptive analysis of the characteristics of attenders/non-attenders, 2) unadjusted and adjusted Poisson regression to examine associations of patient characteristics and uptake of health checks, and 3) decision tree analyses (CHAID) to examine interaction and homogeneity in patient characteristics among attenders.

Results: Of the overall population 30\% attended. In a nested cohort of people residing in a particularly deprived social housing settlement, $25 \%$ attended. Further, in the overall population, we found an association between the likelihood of taking up a health check and age, sex, country of origin, educational attainment, cohabitation, occupational status, and past medical treatment. In the nested cohort the association between uptake and medical treatment was nonsignificant, while the association between uptake and occupation was limited to people who were employed. These results resonate with past evidence on health check attendance.

Conclusions: Attendance in the 'Your Life - Your Health' program is higher among people of a higher socio-economic status. This should be taken into consideration when analysing and interpreting the overall study effects. Moreover, the results suggest that a targeted approach in the social housing sector could be more effective than a mass screening approach. However, more information is required to make such assertion definitive.
\end{abstract}

Keywords: Health check, Health examination, Attendance, Uptake, Community health services, Social deprivation, Socially deprived areas, Social housing sector

\footnotetext{
* Correspondence: Iblarsen@health.sdu.dk

1 Department of Public Health, Research Unit of General Practice, University

of Southern Denmark, Odense, Denmark

Full list of author information is available at the end of the article
}

(c) The Author(s). 2018 Open Access This article is distributed under the terms of the Creative Commons Attribution 4.0 International License (http://creativecommons.org/licenses/by/4.0/), which permits unrestricted use, distribution, and reproduction in any medium, provided you give appropriate credit to the original author(s) and the source, provide a link to the Creative Commons license, and indicate if changes were made. The Creative Commons Public Domain Dedication waiver (http://creativecommons.org/publicdomain/zero/1.0/) applies to the data made available in this article, unless otherwise stated. 


\section{Background}

Poor uptake among socio-economically disadvantaged and susceptible populations is a well-known challenge of general health check interventions, and is widely cited as one of the reasons for the lack of population level effects seen in many studies [1-5].

Due to suboptimal care and under-diagnosing among the socio-economically disadvantaged populations targeted interventions aimed at high-risk groups may contribute to increased socio-economic equity in terms of cardiovascular morbidity and mortality [6].

Risk-scoring is a widely recommended approach to identify high-risk groups in the general population [7]. However, an evaluation of risk scores demonstrates that neglect of social deprivation as a risk factor exacerbates social inequality in health [8]. In the UK, the National Health Service (NHS) Health Check identifies high-risk groups based on a combination of medical health record information and an area based deprivation score, the Townsend Deprivation Index [9, 10]. In accordance with the aforementioned evaluation of risk-scores, a recent assessment of the first 4 years of the NHS Health Check service indicates higher uptake among low socioeconomic status (SES) populations than other SES populations [11].

Comprehensive medical record information on social deprivation is mostly unavailable for population health purposes. An alternative to risk-scores as the one used in the UK may be to target high-risk groups by using an area-based approach alone. The potential impact of a targeted strategy aimed at socially deprived areas has been shown in a Scottish simulation study, comparing mass screening and targeted screening of residents in socially deprived areas [12]. Under the assumption of 1) equal uptake independent of the level of deprivation and 2) a higher proportion of people at risk the higher the level of deprivation, the simulation suggest that the number needed to screen (NNS) to identify one at-risk patient were 16 using mass screening and 6 using targeted screening in socially deprived areas.

In the present study, we report on patient characteristics among attendees and non-attendees of health checks made available only to residents in the social housing sector of the municipality of Aarhus as a novel area-based approach to target health checks that can serve as an alternative to a risk-score based approach when medical information is unavailable for population health purposes. We focus on this general population, as well as a particular sub-group living in an exceptionally deprived social housing area, and discuss the properties of intervention uptake that we need to be aware of to qualify and compare the effects of general versus targeted health checks in socially deprived areas.

\section{Method}

This study uses a cross-sectional method to look at patient characteristics in a sample of 6650 residents of the Aarhus social housing sector who were invited for a health check in the first year of the 'Your Life - Your Health' program.

The 'Your Life - Your Health' program is a three-year prevention and health promotion initiative initiated and funded by the municipality of Aarhus. The applied research aims to evaluate the real-world effects of health checks and subsequent behaviour-change interventions, and/or medical treatment among people residing in the Danish social housing sector. The Danish social housing sector is a non-profit sector comprising apartment buildings for the purpose of providing affordable and decent housing to people in need. The social housing sector population is characterised by high rates of unemployment, with many receiving social welfare. Ethnic minorities are also overrepresented in this sector (Table 1).

\section{Population and sampling}

A total of 19.874 citizens, born between 1943 and 1968 (45 to 70 years of age at the time of invitation), were sampled to participate in the 'Your Life - Your Health' program during three consecutive years starting from September 2014. The study population consisted of a closed cohort of 6.650 participants pre-randomized to enter the program during the first year of the three-year program. The pre-randomization sampling was based on the unique Danish Civil Registration Number system, as well as on residency in the social housing sector in the municipality of Aarhus (330.000 inhabitants) [13]. Due to unforeseen delays in the implementation of the program, people allocated to the first year were invited for health checks from the beginning of September 2014 to the end of February 2016.

\section{Setting}

The health checks took place at two municipal health centres: 1) a central health centre, and 2) a satellite health centre. Municipal health centres are administered and funded by the municipality and represent the principal arena for primary preventive services in the Danish health care sector. This includes lifestyle counselling and training, and secondary prevention in the form of patient education aimed at chronic disease prevention such as type-2 diabetes (T2DM), cardiovascular disease (CVD), chronic obstructive pulmonary disease (COPD), low back pain and stress. The municipal health centres are staffed by health professionals from various professions, including nurses, physiotherapists, dieticians, and occupational therapists.

The central health centre is located in the city centre of Aarhus, the second largest town in Denmark with an 
Table 1 Socio-demographic profile of the population in the Municipality of Aarhus, the social housing sector in the municipality and in the socially deprived settlement of the satellite health centre (Information retrieved from the social registry of the Municipality of Aarhus)

\begin{tabular}{llll}
\hline (November, 2013) & Municipality of Aarhus $(N=330.000)$ & $\begin{array}{l}\text { Social housing sector in the } \\
\text { municipality of Aarhus }(N=75.500)\end{array}$ & $\begin{array}{l}\text { Deprived social housing } \\
\text { settlement }(N=6650)\end{array}$ \\
\hline Unemployment rate $^{\mathrm{a}, \mathrm{b}}$ & $17.0 \%$ & $37.5 \%$ & $52.4 \%$ \\
Social welfare recipients $^{\mathrm{b}}$ & $11.5 \%$ & $27.7 \%$ & $37.2 \%$ \\
Non-western origin $^{c}$ & $10.7 \%$ & $30.3 \%$ & $79.7 \%$ \\
\hline
\end{tabular}

${ }^{\text {ancludes students }}$

bage 18 to 64

'Total population

inner urban city population of approx. 270.000 people. The satellite health centre is located in a socially deprived area in the city of Aarhus with a total population of 6650 people (Table 1). All participants $(N=1407)$ who were invited to a health check at the satellite health centre resided in this particular socially deprived area. A few of these participants $(N=7)$, however, were examined at the central health centre due to patient delay between the invitation and the examination. All other participants were invited to a health check at the central health centre $(N=5243)$.

\section{Invitation}

Invitations were sent out by mail to the participants on a random and on-going basis during the period from the beginning of September 2014 to the end of February 2016. The invitations included an information leaflet and a pre-booked date and time for the health check. The original Danish invitation was translated into English, Arabic, Turkish, and Somali, while the information leaflet was in Danish only.

The pre-booked date and time had to be confirmed by the invited person by text message, telephone, or on the project homepage within 7 days of receiving the invitation. Pre-booked appointments could be postponed (e.g. in case of pregnancy, planned surgery, illness, or if having had a recent health check at the general practitioner). People who did not respond to the invitation were sent a reminder 3 weeks after the initial invitation. No further action was taken to contact non-responders.

\section{Intervention}

\section{Self-reported questionnaire on health and health behavior}

Prior to the health check, citizens were kindly asked to visit the project homepage and fill in a questionnaire on self-reported health (SF-12) and health behavior (physical activity, smoking, alcohol consumption, and diet). They were also asked to provide consent for their information to be used for research purposes related to the project, and to have the results from the questionnaire and health check forwarded to the their general practitioner (GP). The information from the questionnaire was readily available to the municipal health professional undertaking the health check and counselling.

The questionnaire and the consent form were only available in Danish. If the person did not speak or understand Danish she could fill in the questionnaire at the health centre with the help of the health professional undertaking the health check.

\section{Health check}

The health check consisted of a health counselling session and an examination, and lasted an average of $1 \mathrm{~h}$. The time was equally spent for counselling and examination. The examination included measurements of blood pressure, HbA1c, cholesterols, and lipid levels, in addition to weight, height, and waist circumference. Furthermore, measures of fitness level and maximal oxygen consumption (based on a bike exercise test) were obtained. The native language of the health professionals performing the counselling and examination was Danish. Interpreters were not available, if needed the patient could bring a friend or family member.

At the end of the health check, the patient was given a written feedback report, summarizing the results from the questionnaire and the examination.

\section{Data analysis}

Data from the entire cohort as well as data exclusively from the socially deprived area were analysed. No statistical inferences were made between the two cohorts. The analyses consisted of 1) descriptive analysis of the characteristics of attenders/non-attenders, 2) unadjusted and adjusted Poisson regression to examine associations of patient characteristics and uptake of health checks, and 3) decision tree analyses (CHAID) to examine interaction and homogeneity in patient characteristics among attenders [14].

\section{Inclusion and exclusion criteria}

Participants who fulfilled the following criteria were excluded from the analyses: Persons who had died before the scheduled health check, and persons who had moved from the municipality of Aarhus before the health check. 
The only inclusion criterion of the nested cohort of residents from the socially deprived settlement was residency in the settlement at the time of invitation.

\section{Causal model}

A causal direct acyclic graph (DAG) model was developed to guide the adjustments for confounders in the Poisson regression models. We used guidelines from www.dagitty.net to inform the statistical analysis of the association between patient characteristics and uptake of health checks [15]. With attendance to health checks as the outcome variable we built the DAG model on the current evidence on the determinants of attendance to health checks and the model of health care use, proposed by Andersen [16]. The model states that the use of health care is determined by environmental factors surrounding the health care sector, the characteristics of the health care system, and the expected outcome of using health services. Also of relevance are the predisposing characteristics of the patient, enabling factors in his/her environment, as well as the patient's general need for health care, and his/her health behavior.

The DAG is included in Additional file 1 as well as a review of the current evidence base on the determinants of attending health checks.

\section{Variables}

Outcome variable Health check attendance was used as the main outcome variable. It was specified in terms of attenders (people who attended the health check) and non-attenders (people who did not attend the health check).

Exposure variables Exposure variables included patient characteristics identified in the DAG as determinants of uptake of health checks, as well as age, sex, country of origin, education, occupation, income, medical treatment, frequent attendance at GP, preventive consultations at GP, partner in project. All variables except for partner in project were retrieved from Statistics Denmark and the Danish Health Data Authority, and linked with variables from the 'Your Life - Your Health' program using the unique Danish civil registration number [17-22].

Age was defined as age at date of invitation and categorized in five-year age intervals. Date of invitation was missing for 363 people. Missing values were assigned the age of the person at the first of June 2015 as this date is the median date in the study period. No other assignments were made.

Educational level was defined as the highest degree of formal education completed by the first of October 2014. Educational level was classified according to the
UNESCO categories and categorized into three groups: $\leq 10$ years of education, $11-15$ years of education, and $>15$ years of education [23].

Occupation was defined as the occupational status ultimo November 2013. Occupation was categorized into five groups: being employed, self-employed, unemployed/on benefits, social welfare recipients or other. Unemployment benefits are for people who have been unemployed for less than 2 years and who are member of a voluntary unemployment benefit fund. Social welfare recipients are for unemployed people who are not member of an unemployment benefit fund or have been unemployed for more than 2 years. Basic social welfare represents $60 \%$ of the value of basic unemployment benefits. Others include, amongst others, a non-working person from a family that rely on one income only.

OECD-adjusted income level was defined by the household's mean annual net income for the period 2011-2013, and adjusting this figure for family size, where the first adult would count for one, other adults and children above 14 years of age would count for 0.5 , and children below 14 years of age would count for 0.3 [24]. In the absence of national poverty levels family's available income was categorized into quartiles; Low (below 50\% of median), middle-low, middle-high and high (50\% above median).

Cohabitation data was retrieved from Statistics Denmark for the year 2015 and categorized in terms of cohabiting or single. Cohabitation was defined as two adults residing at the same address and who were either married, in a registered partnership, living together with at least one common child, or were born within 15 years of one another.

Information about participants' country of origin was retrieved from Statistics Denmark for the year 2014 in order to reduce the amount of missing data due to people moving out of the specified social housing area. Country of origin was further categorized into three groups: western immigrants (person emigrated from a western country), non-western immigrants (person emigrated from a non-western country), or Danish (rest of the population).

We used participant's use of particular prescription medication as an indicator of received medical treatment. Specifically, participants were categorised as receiving, or as having received medical treatment if they had been prescribed drugs included in the Anatomical Therapeutic Chemical (ATC) Classification System codes of CO (cardiovascular system), A10 (drugs used in diabetes), R03 (drugs for obstructive airways diseases), N05A (antipsychotics), N05B (anxiolytics) and N06A (antidepressants) from Danish pharmacies during the period of January 2012 through to end of August 2014. Medical treatment was coded as a binary yes/no variable. 
The frequency with which participants saw their GP was determined by the mean number of kept face-toface appointments (administrative code 0101) and telephone consultations (administrative code 0201) with the GP during daytime hours between 2011 and 2013. Attenders were categorized as frequent attenders and others, where the former category represented the top $10 \%$ of people who were in touch with their GP the most $[25,26]$.

Participants, who had attended preventive consultations (administrative code 0120) at the GP during daytime hours in the two consecutive calendar years 2012 and 2013, were coded as a binary yes/no variable. The administrative code for preventive consultations includes counselling on both primary and secondary prevention and is thus used for both people at risk and people already in treatment.

Partner in project describes whether your partner, if cohabiting, attended a health check or not. Partner in project is categorised as a Yes/No and was derived from project data.

\section{Confounding variables}

A neighbourhood social deprivation score was calculated from a score developed by Bender et al. to examine the association between neighbourhood social deprivation and participation in general health checks [27]. The score is based on the proportion of people with basic education, rates of unemployment, and the proportion of people in the lowest income quartile in Denmark and categorized into quartiles high/middle high/middle low/ low neighbourhood social deprivation. Information for the score was retrieved from the nationwide Danish social registries on health and social issues for all census districts in Denmark. In this way we could generate accurate local deprivation scores that reflect the relative social deprivation of the individual census districts in the municipality of Aarhus and nationally [17].

\section{Statistical analysis}

Characteristics of attenders and non-attenders are presented and compared using the chi-square test for comparison of proportions. Associations are presented as crude estimates for all exposure variables as well as estimates adjusted for age and sex and multivariable analyses minimally adjusted according to the DAG causal model. All estimates were 372 analysed using Poisson regression. For interpretative purposes Poisson regression and incidence rate ratios (IRR) was chosen over logistic regression and odds ratios (OR). The dependent variable attendance is hence understood as a continuous variable with counts being 0 or 1 .

The Poisson regression was performed with robust error variance and presented with p-values and 95\% confidence intervals (CI) of the IRR. Estimates are presented for the entire cohort of residents of the social housing sector, and for the nested cohort of residents of the socially deprived settlement.

A chi-squared automatic interaction detection (CHAID) decision tree analysis was performed to detect interaction between exposure variables, and to divide data into more homogenous groups [14]. The CHAID analysis groups variables into mutually exclusive subsets based on homogeneity through a series of chi-square tests. The grouping eventually ends up in a hierarchical order of optimal splits of nodes with the most explanatory exposure variable ranked at the top of the hierarchy. Patient characteristics and neighbourhood deprivation were used as categorical input for the CHAID analysis. The CHAID analysis was run with parent nodes defined at a minimum of 200 persons, child nodes defined at a minimum of 20 persons, and significance $\left(\alpha_{\text {merge }}, \alpha_{\text {split }}\right.$, and $P$-value) set at $\leq 0.05$.

Statistical analyses were performed using Stata14.

\section{Results}

The study population consisted of 6650 persons. As one person died before the health check the statistical analyses were performed with $N=6649$ persons. The attendance rate was $30 \%$ in the entire cohort and $25 \%$ in the nested cohort (Table 2). People with non-Danish origin constituted $30 \%$ of the entire cohort and originating from 92 countries, and $57 \%$ of the nested cohort originating from 53 countries. Social welfare recipients represented 53 and $63 \%$ of the overall and the nested cohorts, respectively. About half lived alone and $60 \%$ received medical treatment. In the nested cohort $37 \%$ had less than 10 years of formal education while $51 \%$ belonged to the lowest income quartile.

\section{Uptake in the entire cohort}

Uptake in the entire cohort increased with age, was higher among women and people of Danish or western origin compared to people of non-western origin (Table 3). Adjusted estimates showed an association between uptake and increasing educational level, occupational status, cohabiting and not receiving medical treatment. Income, frequency of attendance at the GP, being registered with a preventive consultation at the GP, or whether your partner had also been invited to participate showed no impact on uptake (Table 3).

The CHAID analysis of the entire cohort shows that education was the strongest predictor of attendance followed by age, and occupational status (Fig. 1). The CHAID also indicate large differences in the absolute uptake. A mere $19 \%$ of people with less than 10 years of education, who live in neighbourhoods with high deprivation, and who are not employed attended the health checks. By contrast, the uptake was as high as $52 \%$ among people 
Table 2 Crude estimates of the association between an exposure and attendance to the health check in the entire cohort and the nested cohort of residents invited to the satellite health centre

\begin{tabular}{|c|c|c|c|c|c|c|c|c|}
\hline & Entire cohort & & & & Nested cohc & & & \\
\hline & Attendance & Non-attendance & Total & Missings & Attendance & Non-attendance & Total & Missings \\
\hline$n(p c t)$ & $1958(29.5)$ & 4691 (70.6) & $6649(100)$ & $0 / 6649$ & $355(25.2)$ & $1052(74.8)$ & $1407(100)$ & $0 / 1407$ \\
\hline Age at first invitation & & & & $0 / 6649$ & & & & $0 / 1407$ \\
\hline-49 & $332(17.0)$ & $1039(22.2)$ & $1371(20.6)$ & & $60(16.9)$ & $268(25.5)$ & $328(23.3)$ & \\
\hline $50-54$ & $442(22.6)$ & $1065(22.7)$ & $1507(22.7)$ & & $90(25.4)$ & $237(22.5)$ & $327(23.2)$ & \\
\hline $55-59$ & $413(21.1)$ & $963(20.5)$ & $1376(20.7)$ & & $71(20.0)$ & $200(19.0)$ & $271(19.3)$ & \\
\hline $60-64$ & $367(18.7)$ & $766(16.3)$ & $1133(17.0)$ & & $62(17.5)$ & $169(16.1)$ & $231(16.4)$ & \\
\hline $65+$ & 404 (20.6) & $858(18.3)$ & $1262(19.0)$ & & $72(20.3)$ & $178(16.9)$ & $250(17.8)$ & \\
\hline Sex & & & & $0 / 6649$ & & & & $0 / 1407$ \\
\hline Female & $1107(56.5)$ & $2397(51.1)$ & $3504(52.7)$ & & $195(54.9)$ & $466(44.3)$ & $661(47.0)$ & \\
\hline Male & $851(43.5)$ & $2294(48.9)$ & 3145 (51.9) & & $160(45.1)$ & $586(55.7)$ & $746(53.0)$ & \\
\hline Education (years) & & & & $432 / 6649$ & & & & $180 / 1407$ \\
\hline$<=10$ & $479(25.8)$ & $1575(36.1)$ & 2054 (33.0) & & $89(28.2)$ & 361 (39.6) & $450(36.7)$ & \\
\hline $10-15$ & $832(44.8)$ & $1822(41.8)$ & $2654(42.7)$ & & $140(44.3)$ & $371(40.7)$ & $511(41.7)$ & \\
\hline$>15$ & $547(29.4)$ & $962(22.1)$ & $1509(24.3)$ & & $87(27.5)$ & 179 (19.7) & $266(21.7)$ & \\
\hline Income (1000 dkk) & & & & $6 / 6649$ & & & & $3 / 1407$ \\
\hline Low quartile (0-) & $581(29.7)$ & $1734(37.0)$ & $2315(34.9)$ & & $157(44.2)$ & $556(53.0)$ & $713(50.8)$ & \\
\hline Middle low quartile (161-) & 756 (38.6) & $1836(39.2)$ & $2592(39.0)$ & & $108(30.4)$ & $355(33.8)$ & $463(33.0)$ & \\
\hline Middle high quartile (216-) & $437(22.3)$ & $815(17.4)$ & $1252(18.9)$ & & $68(19.2)$ & $116(11.1)$ & $184(13.1)$ & \\
\hline High quartile (283-) & $184(9.40)$ & $300(6.40)$ & $484(7.29)$ & & $22(6.20)$ & $22(2.10)$ & $44(3.13)$ & \\
\hline Occupational status & & & & $5 / 6649$ & & & & $3 / 1407$ \\
\hline Employed & $870(44.4)$ & $1616(34.5)$ & $2486(37.4)$ & & $133(37.5)$ & $251(23.9)$ & $384(27.4)$ & \\
\hline Self-employed & $43(2.20)$ & $78(1.66)$ & $121(1.82)$ & & $6(1.69)$ & $22(2.10)$ & $28(2.00)$ & \\
\hline Unemployed/benefits & $84(4.29)$ & $191(4.08)$ & $275(4.14)$ & & $18(5.07)$ & $41(3.91)$ & $59(4.20)$ & \\
\hline Social welfare recipients & $898(45.9)$ & $2639(56.3)$ & $3537(53.2)$ & & $183(51.5)$ & $701(66.8)$ & $884(63.0)$ & \\
\hline Others & $63(3.22)$ & $162(3.46)$ & $225(3.39)$ & & $15(4.23)$ & $34(3.24)$ & 49 (3.49) & \\
\hline Country of origin & & & & $0 / 6649$ & & & & $0 / 1407$ \\
\hline Denmark & $1429(73.0)$ & $3227(68.8)$ & $4656(70.0)$ & & $176(49.6)$ & $430(40.9)$ & $606(43.1)$ & \\
\hline Western & $107(5.46)$ & 185 (3.94) & $292(4.39)$ & & $23(6.48)$ & $47(4.47)$ & $70(4.98)$ & \\
\hline Non-western & $422(21.6)$ & $1279(27.3)$ & $1701(21.1)$ & & $156(43.9)$ & $575(54.7)$ & $731(52.0)$ & \\
\hline Cohabitation & & & & $8 / 6649$ & & & & $3 / 1407$ \\
\hline Single & 1049 (53.6) & $2626(56.1)$ & $3675(55.3)$ & & $151(42.5)$ & $510(48.6)$ & $661(47.1)$ & \\
\hline Cohabiting & $908(46.4)$ & $2058(43.9)$ & $2966(44.7)$ & & $204(57.5)$ & $539(51.4)$ & $743(52.9)$ & \\
\hline Partner in project & & & & $8 / 6649$ & & & & $3 / 1407$ \\
\hline Yes & $729(37.3)$ & $1641(35.0)$ & $2370(35.7)$ & & $150(42.3)$ & $393(37.5)$ & $543(38.7)$ & \\
\hline No & $1228(62.8)$ & $3043(65.0)$ & $4271(64.3)$ & & $205(57.8)$ & $656(62.5)$ & $861(61.3)$ & \\
\hline Neighbourhood deprivation & & & & $7 / 6649$ & & & & $4 / 1407$ \\
\hline Low deprivation & $262(13.4)$ & $600(12.8)$ & $862(13.0)$ & & $14(3.94)$ & $45(4.29)$ & $59(4.21)$ & \\
\hline Low middle deprivation & $423(21.6)$ & $988(21.1)$ & $1411(21.2)$ & & $76(21.4)$ & $174(16.6)$ & $250(17.8)$ & \\
\hline High middle deprivation & $655(33.5)$ & $1389(29.7)$ & $2044(30.8)$ & & $71(20.0)$ & $156(14.9)$ & $227(16.2)$ & \\
\hline High deprivation & 618 (31.6) & 1707 (36.4) & $2325(35.0)$ & & $194(54.7)$ & $673(64.2)$ & $867(61.8)$ & \\
\hline
\end{tabular}


Table 2 Crude estimates of the association between an exposure and attendance to the health check in the entire cohort and the nested cohort of residents invited to the satellite health centre (Continued)

\begin{tabular}{|c|c|c|c|c|c|c|c|c|}
\hline & Entire cohort & & & & Nested coho & & & \\
\hline & Attendance & Non-attendance & Total & Missings & Attendance & Non-attendance & Total & Missings \\
\hline Medical treatment & & & & $0 / 6649$ & & & & $0 / 1407$ \\
\hline Yes & $1118(57.1)$ & $2934(62.6)$ & $4052(60.5)$ & & $209(58.9)$ & $644(61.2)$ & $853(61.3)$ & \\
\hline No & $840(42.9)$ & $1757(37.5)$ & $2597(39.1)$ & & $146(41.1)$ & $408(38.8)$ & $554(39.4)$ & \\
\hline Frequent attenders to GP (top 10\%) & & & & $0 / 6649$ & & & & $0 / 1407$ \\
\hline Yes & $149(7.61)$ & $415(8.85)$ & $564(8.48)$ & & $29(8.17)$ & $81(7.70)$ & $110(7.82)$ & \\
\hline No & $1809(92.4)$ & $4276(91.2)$ & $6085(91.5)$ & & $326(91.8)$ & $971(92.3)$ & $1297(92.2)$ & \\
\hline Preventive consultation at GP & & & & $0 / 6649$ & & & & $0 / 1407$ \\
\hline Yes & $506(25.8)$ & $1271(27.1)$ & $1777(26.7)$ & & $95(26.8)$ & $278(26.4)$ & $373(26.5)$ & \\
\hline No & $1452(74.2)$ & $3420(72.9)$ & 4872 (73.3) & & $260(73.2)$ & 774 (73.6) & 1034 (73.5) & \\
\hline
\end{tabular}

over 55 years of age with 11 to 15 years of education, an income above the median, and not in treatment. Among people with less than 10 years of education the uptake among self-employed people was significantly higher than all other occupational categories. Among people with more than 15 years of education the uptake among social welfare recipients was lower than other occupational categories.

\section{Uptake in the nested cohort}

The nested cohort likewise showed higher uptake among women and people of Danish and western origin, though age only differed slightly due to a lower uptake among people under the age of 50 (Table 4). Further, the adjusted analysis shows that people with higher education, who are cohabiting (as opposed to living along), and are being employed rather than unemployed is associated with higher uptake (Table 4). Unlike the analysis of the entire cohort, the analysis of the nested cohort suggests that medical treatment has no impact on uptake. Similarly, income, frequent attendance to GP, registration of a preventive consultation at the GP, and whether your partner was invited to participate indicate no impact on the uptake of health checks.

The CHAID analysis show that occupation was the strongest predictor of attendance to the 'Your Live - Your Health' program in the nested cohort. Self-employed are grouped with those receiving social welfare, and employed with their unemployed counterparts who are on benefits. The results indicate lower attendance among selfemployed and social welfare recipients (Fig. 2).

\section{Discussion}

In this study on the patient characteristics of attendees and non-attendees at social housing sector health checks $30 \%$ of the overall population attended scheduled health checks. In a nested cohort of people residing in a particularly deprived social housing settlement, 25\% attended. Comparable differences in uptake were seen in a Dutch study on health checks inviting an underserved population using postal invitations [28]. Further, in the overall population, we found an association between the likelihood of taking up an offer of a health check and age, sex, country of origin, educational attainment, cohabitation, occupational status, and past medical treatment. In the nested cohort the association between uptake and medical treatment was non-significant, while the association between uptake and occupation was limited to people who were employed. These results resonate with past evidence on health check attendance [1]. In addition, A CHAID analysis of interaction and homogeneity of the entire cohort demonstrates that education is the strongest predictor of uptake, followed by age, and occupational status. In the nested cohort the strongest predictor was occupational status, followed by age. The CHAID furthermore group occupational status in self-employed and social-welfare recipients or employed and people on unemployment benefits. This grouping was not seen in a comparable study in a neighbouring municipality showing similar uptake among employed and self-employed hand lowest uptake among social welfare recipients [29] .The grouping of employed and short-term unemployed may be due to the fact that unemployment benefits only lasts 2 years and that these people are formerly employed and likely and to re-enter the labor market within a short time-span. The grouping of the self-employed and people on social welfare is not as obvious but may be due to an unusually low attendance among a small group of self-employed $(N=28,2 \%$ of the nested cohort), and not so much that these groups share reasons for non-attendance.

The low uptake of preventive studies and studies in general from residents of deprived settlements and ethnic minorities is well established $[1,30]$. In the 'Your Life Your Health' program social welfare recipients and people with non-Danish origin represent more than half of the 
Table 3 Adjusted estimates of the association between an exposure and attendance to the health check in the entire cohort

\begin{tabular}{|c|c|c|c|c|c|c|}
\hline & \multicolumn{2}{|l|}{ Model 1 (crude) } & \multicolumn{2}{|c|}{ Model 2 (adjusted for age and sex) } & \multicolumn{2}{|c|}{ Model 3 (minimal adjustment) } \\
\hline & IRR $(95 \% \mathrm{Cl})$ & $p$-value & & $p$-value & IRR $(95 \% \mathrm{Cl})$ & $p$-value \\
\hline \multicolumn{7}{|l|}{$\mathrm{Age}^{\mathrm{a}}$} \\
\hline-49 & $1(-;-)$ & & $1(-;-)$ & & $1(-;-)$ & \\
\hline $50-54$ & $1.21(1.07 ; 1.37)$ & 0.002 & $1.21(1.07 ; 1.37)$ & 0.002 & $1.21(1.07 ; 1.37)$ & 0.002 \\
\hline $55-59$ & $1.24(1.10 ; 1.40)$ & 0.001 & $1.24(1.10 ; 1.41)$ & 0.001 & $1.24(1.10 ; 1.40)$ & 0.001 \\
\hline $60-64$ & $1.34(1.18 ; 1.52)$ & 0.000 & $1.34(1.18 ; 1.52)$ & 0.000 & $1.34(1.18 ; 1.52)$ & 0.000 \\
\hline $65+$ & $1.32(1.17 ; 1.50)$ & 0.000 & $1.32(1.17 ; 1.49)$ & 0.000 & $1.32(1.17 ; 1.50)$ & 0.000 \\
\hline \multicolumn{7}{|l|}{$\operatorname{Sex}^{\mathrm{a}}$} \\
\hline Female & $1(-;-)$ & & $1(-;-)$ & & $1(-;-)$ & \\
\hline Male & $0.86(0.80 ; 0.92)$ & 0.000 & $0.86(0.79 ; 0.92)$ & 0.000 & $0.86(0.79 ; 0.92)$ & 0.000 \\
\hline \multicolumn{7}{|l|}{ Country of Origen ${ }^{a}$} \\
\hline Denmark & $1(-;-)$ & & $1(-;-)$ & & $1(-;-)$ & \\
\hline Western & $1.20(1.02 ; 1.40)$ & 0.027 & $1.21(1.03 ; 1.41)$ & 0.020 & $1.19(1.02 ; 1.40)$ & 0.027 \\
\hline Non-western & $0.81(0.74 ; 0.89)$ & 0.000 & $0.85(0.77 ; 0.93)$ & 0.001 & $0.81(0.74 ; 0.89)$ & 0.000 \\
\hline \multicolumn{7}{|l|}{ Education $^{\mathrm{b}}$} \\
\hline$<=10$ & $1(-;-)$ & & $1(-;-)$ & & $1(-;-)$ & \\
\hline $10-15$ & $1.34(1.22 ; 1.48)$ & 0.000 & $1.37(1.25 ; 1.51)$ & 0.000 & $1.36(1.24 ; 1.50)$ & 0.000 \\
\hline$>15$ & $1.56(1.40 ; 1.72)$ & 0.000 & $1.57(1.42 ; 1.74)$ & 0.000 & $1.56(1.41 ; 1.73)$ & 0.000 \\
\hline \multicolumn{7}{|l|}{ Occupational status ${ }^{\mathrm{c}}$} \\
\hline Employed & $1.38(1.28 ; 1.49)$ & 0.000 & $1.51(1.39 ; 1.64)$ & 0.000 & $1.38(1.26 ; 1.51)$ & 0.000 \\
\hline Self-employed & $1.40(1.10 ; 1.79)$ & 0.008 & $1.59(1.25 ; 2.03)$ & 0.000 & $1.46(1.14 ; 1.87)$ & 0.003 \\
\hline Unemployed/benefits & $1.20(1.00 ; 1.45)$ & 0.053 & $1.38(1.14 ; 1.67)$ & 0.001 & $1.27(1.04 ; 1.54)$ & 0.018 \\
\hline Social welfare recipients & $1(-;-)$ & & $1(-;-)$ & & $1(-;-)$ & \\
\hline Others & $1.10(0.89 ; 1.37)$ & 0.377 & $1.80(1.14 ; 2.85)$ & 0.012 & $1.76(1.09 ; 2.83)$ & 0.021 \\
\hline \multicolumn{7}{|l|}{ Income ${ }^{d}$} \\
\hline Low quartile & $1(-;-)$ & & $1(-;-)$ & & $1(-;-)$ & \\
\hline Middle low quartile & $1.16(1.06 ; 1.28)$ & 0.001 & $1.13(1.03 ; 1.24)$ & 0.012 & $1.05(0.95 ; 1.17)$ & 0.339 \\
\hline Middle high quartile & $1.39(1.25 ; 1.54)$ & 0.000 & $1.37(1.23 ; 1.52)$ & 0.000 & $1.10(0.97 ; 1.25)$ & 0.126 \\
\hline High quartile & $1.52(1.33 ; 1.73)$ & 0.000 & $1.47(1.29 ; 1.69)$ & 0.000 & $1.14(0.97 ; 1.33)$ & 0.108 \\
\hline \multicolumn{7}{|l|}{ Cohabitation $^{c}$} \\
\hline Single & $1(-;-)$ & & $1(-;-)$ & & $1(-;-)$ & \\
\hline Cohabiting & $1.07(1.00 ; 1.16)$ & 0.066 & $1.09(1.01 ; 1.17)$ & 0.023 & $1.11(1.03 ; 1.20)$ & 0.007 \\
\hline \multicolumn{7}{|l|}{ Medical treatment ${ }^{\mathrm{e}}$} \\
\hline Yes & $1(-;-)$ & & $1(-;-)$ & & $1(-;-)$ & \\
\hline No & $1.17(1.09 ; 1.26)$ & 0.000 & $1.23(1.14 ; 1.33)$ & 0.000 & $1.22(1.13 ; 1.32)$ & 0.000 \\
\hline \multicolumn{7}{|l|}{ Frequent attendance ${ }^{f}$} \\
\hline Yes & $1(-;-)$ & & $1(-;-)$ & & $1(-;-)$ & \\
\hline No & $1.13(0.98 ; 1.30)$ & 0.106 & $1.17(1.01 ; 1.35)$ & 0.035 & $0.98(0.84 ; 1.13)$ & 0.753 \\
\hline \multicolumn{7}{|l|}{ Preventive consultation ${ }^{g}$} \\
\hline Yes & $1(-;-)$ & & $1(-;-)$ & & $1(-;-)$ & \\
\hline No & $1.05(0.96 ; 1.14)$ & 0.295 & $1.10(1.00 ; 1.20)$ & 0.040 & $1.00(0.91 ; 1.10)$ & 0.994 \\
\hline
\end{tabular}


Table 3 Adjusted estimates of the association between an exposure and attendance to the health check in the entire cohort (Continued)

\begin{tabular}{|c|c|c|c|c|c|c|}
\hline & \multicolumn{2}{|l|}{ Model 1 (crude) } & \multicolumn{2}{|c|}{ Model 2 (adjusted for age and sex) } & \multicolumn{2}{|c|}{ Model 3 (minimal adjustment) } \\
\hline & $\operatorname{IRR}(95 \% \mathrm{Cl})$ & $p$-value & & $p$-value & IRR $(95 \% \mathrm{Cl})$ & $p$-value \\
\hline \multicolumn{7}{|c|}{ Partner in project ${ }^{\text {h }}$} \\
\hline Yes & $1(-;-)$ & & $1(-;-)$ & & $1(-;-)$ & \\
\hline No & $0.94(0.87 ; 1.01)$ & 0.084 & $0.94(0.87 ; 1.01)$ & 0.096 & $0.98(0.85 ; 1.12)$ & 0.732 \\
\hline
\end{tabular}

Model 3 adjustments

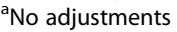

${ }^{\mathrm{b}}$ Age, sex, country of origin

cAge, sex, country of origin, education

${ }^{\mathrm{d}}$ Age, sex, country of origin, education, occupation

${ }^{\mathrm{e}}$ Age

${ }^{f}$ Age, sex, education, occupation, cohabitation

${ }^{g}$ Age, sex, medical treatment, education, country of origin, frequent attendance, income, neighbourhood social deprivation, occupation, cohabitation

${ }^{\mathrm{h}}$ Cohabitation

nested cohort. An evaluation of the Danish national health survey shows that the odds of responding to a health survey is three times higher for people with Danish origin compared to people with non-Danish origin (descendants and immigrants) [31]. Even though we see a significantly higher attendance rate among people of Danish origin, the CHAID analysis indicates that educational attainment and occupational status, rather than country of origin, are the strongest predictors of attendance. In turn, this suggests that the association between attendance and country of origin may be mediated by educational attainment and occupational status. In light of this, efforts to improve the uptake and eliminate the differences we see between attenders and non-attenders should thus target people with low educational level as well as the unemployed. Studies from The Netherlands and Scotland suggest that a face-

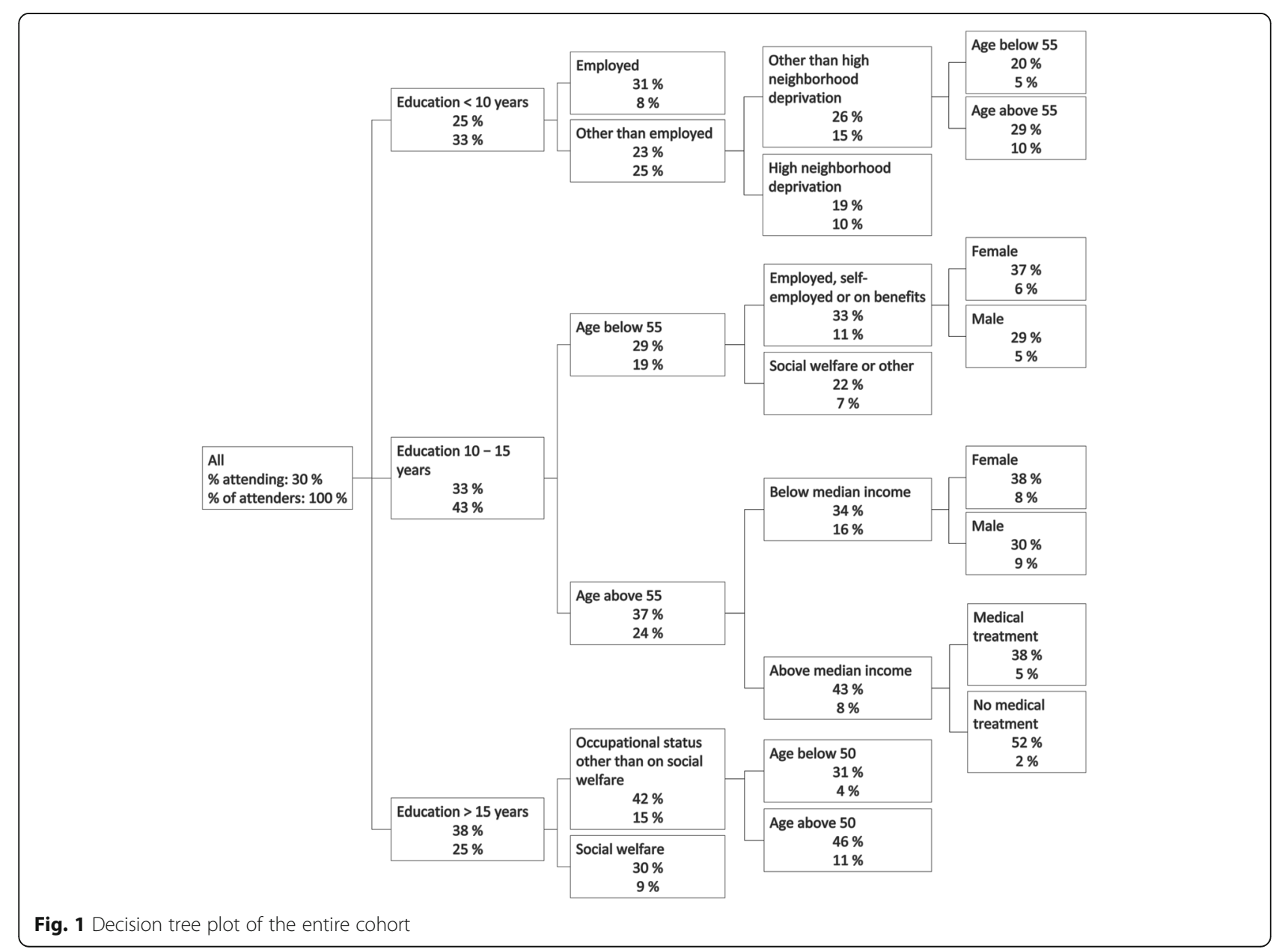


Table 4 Adjusted estimates of the association between an exposure and attendance to the health check in the nested cohort of residents invited to the satellite health centre

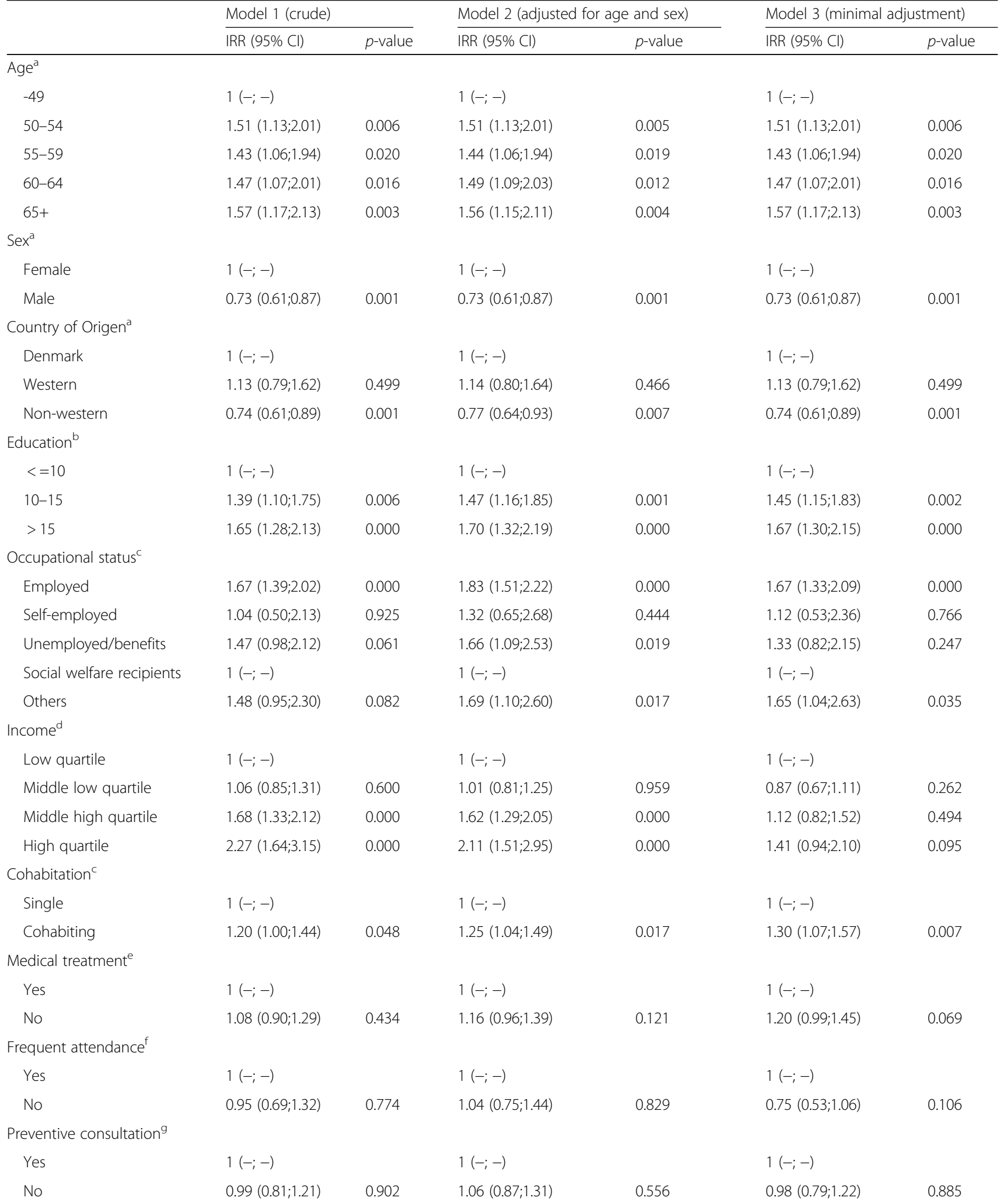


Table 4 Adjusted estimates of the association between an exposure and attendance to the health check in the nested cohort of residents invited to the satellite health centre (Continued)

\begin{tabular}{|c|c|c|c|c|c|c|}
\hline & \multicolumn{2}{|l|}{ Model 1 (crude) } & \multicolumn{2}{|c|}{ Model 2 (adjusted for age and sex) } & \multicolumn{2}{|c|}{ Model 3 (minimal adjustment) } \\
\hline & IRR $(95 \% \mathrm{Cl})$ & $p$-value & IRR $(95 \% \mathrm{Cl})$ & $p$-value & IRR $(95 \% \mathrm{Cl})$ & $p$-value \\
\hline \multicolumn{7}{|c|}{ Partner in project ${ }^{\mathrm{h}}$} \\
\hline Yes & $1(-;-)$ & & $1(-;-)$ & & $1(-;-)$ & \\
\hline No & $0.86(0.72 ; 1.03)$ & 0.108 & $0.89(0.74 ; 1.06)$ & 0.192 & $0.98(0.75 ; 1.28)$ & 0.866 \\
\hline
\end{tabular}

Model 3 adjustments

${ }^{\mathrm{a}}$ No adjustments

${ }^{\mathrm{b}}$ Age, sex, country of origin

${ }^{c}$ Age, sex, country of origin, education

${ }^{d}$ Age, sex, country of origin, education, occupation

${ }^{\mathrm{e}}$ Age

${ }^{f}$ Age, sex, education, occupation, cohabitation

${ }^{g} \mathrm{Age}$, sex, medical treatment, education, country of origin, frequent attendance, income, neighbourhood social deprivation, occupation, cohabitation

${ }^{\mathrm{h}}$ Cohabitation

to-face community-based approach, engaging peers and community leaders in outreach work can increase the attendance at health checks in socially deprived settlements $[32,33]$.

\section{Targeted approach or mass screening}

Two main assumptions underpin the simulation comparing the effects of targeted versus mass screening in
Scotland: 1) The uptake of the two approaches is equal, and 2) a targeted approach will reach a higher proportion of people at risk (not the worried well or people already in treatment) the higher the social deprivation of the area [12].

The veracity of the first assumption of at least comparable uptake of mass screening and targeting socially deprived areas, is brought into question by the five-point

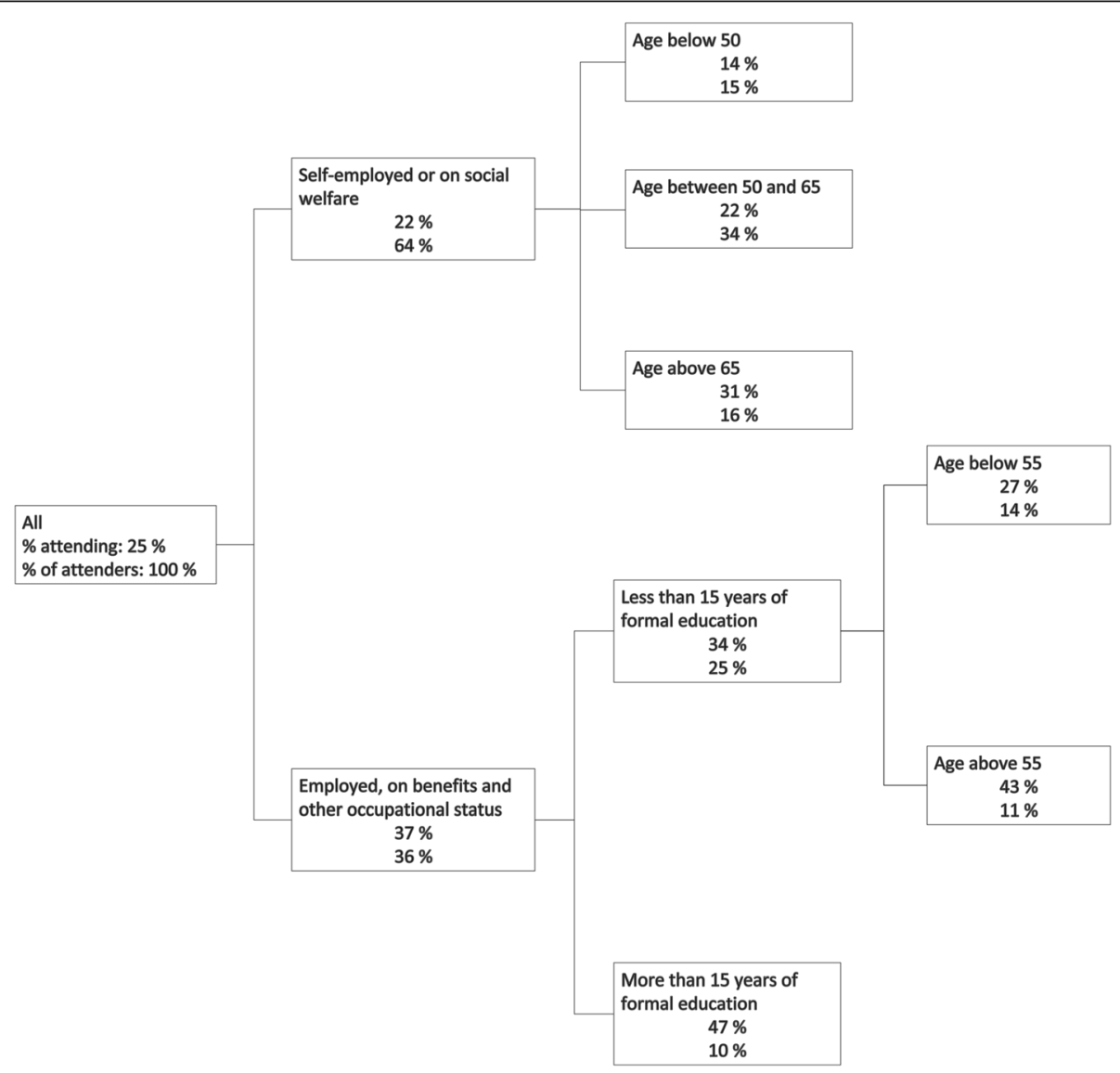

Fig. 2 Decision tree plot of the nested cohort 
discrepancy (30 and 25\%) in uptake of the 'Your Life Your Health' program. A similar study in a neighbouring municipality to Aarhus aimed at the general population had an overall uptake of $55 \%$, but only $37 \%$ in people with low income and low educational level [29]. The simulation from Scotland shows a NNS of 16 in mass screening to identify one individual at high risk for CVD and six in targeted screening in socially deprived areas in other words, a NNS that is 2.7 times lower when targeting socially deprived areas than any mass screening of the general population [12]. An uptake of 30 and $25 \%$ in the social housing sector in general and in a particularly socially derived settlement respectively, equals an attendance rate of between $81 \%$ and 67 in the general population of people residing in the social housing sector in general and in a socially deprived settlement when taking the proportion of people at-risk into consideration. Even though these figures favor the targeted approach used in the 'Your Life - Your Health' program they should be interpreted with caution as the reported attendance rate does not take into account potential confounding variables. These may include differences in context and characteristics of attendees and nonattendees in the two programs. A meta-analysis of the attendance rates in the two programs may be necessary to ascertain whether the targeted approach is more effective than mass screening regardless of varying NNSs.

The second assumption is that the program targets the at-risk population. A Dutch study on cardiovascular screening in general practice in a low socio-economic area suggested that the majority of people in this particular area could be classified as being at risk. Specifically, $60 \%$ of men and women above age 50 and 55 , respectively, were not prescribed medication for hypertension or hypercholesterolemia despite a SCORE risk greater than 5\% [34]. Using a broader definition of medical treatment, 40 and $39 \%$ in the entire cohort and the nested cohort, respectively, were not prescribed medical treatment. Further, people who were prescribed medical treatment were significantly less likely to attend a health check in the entire cohort of the 'Your Life - Your Health' program. In contrast we see no association between being prescribed medical treatment and attendance in the nested cohort. Thus, it would seem that the uptake of the 'Your Life - Your Health' program was comparable for people who had not been prescribed medical treatment and people who had. With the available information we are not able to see whether the program reaches people at risk, that is, attenders not being prescribed medicine with e.g. a SCORE above 5\%, compared to the worried well, that is, attenders with e.g. a SCORE below 5\% and a healthy lifestyle. In the 'Your Life - Your Health' program, increased attendance at health checks was associated with high income, high educational attainment, and employment, with the latter two variables representing the strongest predictors of attendance. Even though the settlements included in the 'Your Life - Your Health' program are more deprived and comprise a population that differs from the general population (Table 1), more health data on the attendees is required to establish whether attendees belong to the at-risk population or the worried well.

A third assumption not mentioned in the simulation from Scotland relates to the idea that an intervention should reach people who are not only at risk but who would not otherwise consult for cardiovascular screening (compliers). If the intervention merely taps populations of people who consult for cardiovascular screening both as part of usual care and when provided the opportunity through an intervention as the one described here (always-users), any effect will likely be negligible as these individuals are already relatively vigilant in attending health checks. In other words, an intervention that fails to reach compliers will in all likelihood contribute little or nothing to population health beyond that of standard care [35]. In the 'Your Life - Your Health' program being registered with an administrative code for a preventive consultation at the GP, or with attendance frequency at the GP had no impact on attendance. Of the two variables, being registered with an administrative code for a preventive consultation at the GP is probably the best proxy for a health check. The code indicates consultations specifically designed for encouraging behavior change or preventive medical treatment. The downside of the administrative code for a preventive consultation is that it is used to denote both primary and secondary prevention. Thus, the mere presence of this administrative code in a patient file, says nothing about whether the patient is at risk of disease, or if he/she is already ill. In light of this, data on biomarkers such as bloodpressure, cholesterol, or blood-sugar levels are required to establish whether intervention effects will be due to the fact, that the intervention reaches compliers and not always-users.

\section{Strengths and limitations}

The main strengths of the present study are the high validity of the registries from Statistics Denmark and the random sampling of a complete cohort of residents from the social housing sector in the municipality of Aarhus [17]. The registries on income and occupational status, and the prescription registry is of very high quality with few missings and as such not prone to information bias $[19,20,22]$. The relatively large proportion of missing data on educational attainment is most likely due to yet-to-be-registered information on immigrants [21]. Nonetheless, missing data could possibly lead to information bias in the 
association between educational attainment and attendance. This, however, does not seem to be the case (Additional file 2). Administrative codes from the primary care sector have not been scrutinized in validation studies and may be prone to misclassification [18]. Contacts such as the 0101 code are registered using a personal health insurance card and is most likely both complete and valid. Contrary, service codes such as 0120 are registered by the GP in addition to each consultation and should be used with care, as they may be prone to misclassification. An evaluation of the administrative code for preventive consultations show large differences between GPs in the use of the code [36].

Another strength is the combination of DAG and CHAID analyses to establish a both theory-driven and data-driven analytical approach. DAGs establishes associations based on theoretical understanding of predictors of uptake of health checks while CHAIDs pinpoints the strongest predictors of attendance based on the available data.

The reliability of the analyses may have been slightly offset by possible residual confounding due to a complex causal model and unavailability of a number of exposures. The causal model is rather complex with a large number of exposures and causal paths. This may give rise to residual confounding due to incorrect causal paths and unavailability of certain confounders - for instance, information on health-risk behaviors, and cognitive variables such as health beliefs, and health literacy. Some of the exposures included in the present analyses - such as age, sex, country of origin, and educational attainment - are time-independent, early-in-life exposures with a rather straightforward analysis. Others, such as occupational status, income, cohabitation, medical treatment, and health-seeking behavior are time-dependent and challenged by reverse causation, collider bias, and residual confounding. However, most of the time-dependant variables are fairly stable over time, limiting challenges with reverse causation. Though some collider stratification bias and residual confounding is likely, the effects of these biases are negligent due to the strong predictive value of educational attainment, occupational status and age as demonstrated in the CHAID analysis.

A final limitation to the study is the high proportion of people of non-Danish origin and the information leaflet and questionnaire being available in Danish only. Firstly, even though the invitation was provided in four other languages than Danish, the Danish-only information leaflet and questionnaire may have had a significant impact on the overall attendance to the health checks. Secondly, even though the consent to use the data from the health check for research purposes was placed at the very end of the questionnaire, someone with poor reading and writing skills, and no help from a peer, could have provided consent without a proper understanding of what they consented to. The same might have been the case when the questionnaire was filled-in at the health centre together with a native Danish speaking health professional without the presence of an authorized interpreter.

\section{Conclusion}

Attendance in the 'Your Life - Your Health' program was generally low and even lower in a sub-group living in an exceptionally deprived social housing area. Attendance was higher among people of a higher socio-economic status, females, people of Danish origin and increased with age. Education was the strongest predictor of attendance in the 'Your Life - Your Health' program. In an exceptionally deprived social housing area occupation was the strongest predictor. Attendance showed no association with income. These findings should be taken into consideration when analysing and interpreting the overall study effects. Moreover, the results suggest that a targeted approach in the social housing sector could be more effective than a mass screening approach. However, more information is required to make such assertion definitive.

\section{Additional files}

Additional file 1: Direct Acyclic Graph (DAC) of determinants of attendance to health checks. (PDF $432 \mathrm{~kb}$ )

Additional file 2: Analysis of the impact of missings in the association between attendance and the variable educational attainment. (PDF $42 \mathrm{~kb}$ )

\section{Abbreviations}

ATC: Anatomical Therapeutic Chemical Classification System; CHAID: Chi-squared automatic interaction detection; COPD: Chronic obstructive pulmonary disease; CVD: Cardiovascular disease; DAG: Direct acyclic graph; GP: General practitioner; IRR: Incidence rate ratio; NHS: National Health Services; NNS: Numbers needed to screen; OECD: Organisation for Economic Co-operation; OR: Odds ratio; SES: Socio-economic status; T2DM: Type-2 Diabetes Mellitus; UNESCO: United Nations Educational, Scientific and Cultural Organisation

\section{Acknowledgements}

The authors like to thank Niels Henrik Bruun, Statistician at the research Unit of General Practice at Aarhus University, for valuable contributions to the statistical analysis of the patient data and Jane Nautrup Østergaard and Trine Vangsted Møller from the Municipality of Aarhus for their insights into the target population, the specific settings and the implementation of the intervention.

\section{Funding}

The 'Your Life - Your Health' program was funded by the Municipality of Aarhus, the Central Denmark Region and Aarhus University. Aarhus University, The Municipality of Aarhus and The Central Denmark Region designed the 'Your Life - Your Health' program. The Municipality of Aarhus and Aarhus University collected the data and Aarhus University analysed and interpreted the data.

\section{Availability of data and materials}

The data that support the findings of this study are available from Statistics Denmark but restrictions apply to the availability of these data, which were used under license for the current study, and so are not publicly available. Data are however available from the authors upon reasonable request and with permission of Statistics Denmark. 


\section{Authors' contributions}

$\mathrm{LBL}$ analyzed and interpreted the patient data and was the main contributor to the manuscript. AS, ALB and JLT contributed to the interpretation of patient data and the manuscript. All authors read and approved the final manuscript.

\section{Authors' information}

AS is primary investigator and ALB is project manager on the research evaluation of 'Your Life - Your Health' program.

\section{Ethics approval and consent to participate}

The project is registered as part of the research projects, covered by the common university notification of the Danish Data Protection Agency (Datatilsynet) on processing personal data, carried out by the university Danish Data Protection Agency's journal no: 2015-57-0002, Aarhus University's journal no: 62908, serial number 188. According to the Act on Research Ethics Review of Health Research Projects (section 14,2) the 'Your Life - Your Health' program does not need ethical approval from a Research Ethics Board [17]. The study complies with the Helsinki Declaration, with written informed consent to use data for research purposes obtained from participants prior to their health check. Participants were anonymized before linking information on attendance and national registers from Statistics Denmark. Data management and data analysis was performed on secure servers at Statistics Denmark.

\section{Competing interests}

The authors declare that they have no competing interests.

\section{Publisher's Note}

Springer Nature remains neutral with regard to jurisdictional claims in published maps and institutional affiliations.

\section{Author details}

'Department of Public Health, Research Unit of General Practice, University of Southern Denmark, Odense, Denmark. ${ }^{2}$ Department of Public Health, Section of General Practice, Aarhus University, Aarhus, Denmark. ${ }^{3}$ The Research Unit for General Practice, Aarhus University, Aarhus, Denmark. ${ }^{4}$ Department of Clinical Medicine, Research Unit for General Practice, Aalborg University, Aalborg, Denmark.

\section{Received: 16 September 2017 Accepted: 25 April 2018}

\section{Published online: 02 May 2018}

\section{References}

1. Dryden R, Williams B, McCowan C, Themessl-Huber M. What do we know about who does and does not attend general health checks? Findings from a narrative scoping review. BMC Public Health. 2012;12:723.

2. Krogsbø|l LT, Jørgensen KJ, Grønhøj Larsen C, Gøtzsche PC. General health checks in adults for reducing morbidity and mortality from disease: Cochrane systematic review and meta-analysis. BMJ. 2012;345:e7191.

3. Bender AM, Jørgensen T, Helbech B, Linneberg A, Pisinger C. Socioeconomic position and participation in baseline and follow-up visits: the Inter99 study. Eur J Prev Cardiol. 2014:21:899-905.

4. Bender AM, Jørgensen T, Pisinger C. Is self-selection the main driver of positive interpretations of general health checks? The Inter99 randomized trial. Prev Med. 2015;81:42-8.

5. Bender AMF, Jørgensen T, Pisinger C. Effects of general health checks differ under two different analyses perspectives - the Inter99 randomized study. J Clin Epidemiol. 2016;71:120-2.

6. Capewell S, Graham H. Will cardiovascular disease prevention widen health inequalities? PLoS Med. 2010;7:e1000320.

7. Piepoli MF, Hoes AW, Agewall S, Albus C, Brotons C, Catapano AL, et al. 2016 European guidelines on cardiovascular disease prevention in clinical practice. Eur Heart J. 2016;37:2315-81.

8. Tunstall-Pedoe H, Woodward M. By neglecting deprivation, cardiovascular risk scoring will exacerbate social gradients in disease. Heart. 2006;92:307-10.

9. Dalton ARH, Soljak M. The nationwide systematic prevention of cardiovascular disease: the UK's health check programme. J Ambul Care Manage. 2012;35: 206-15.
10. Dekker JM, Alssema M, Janssen P, Van der Paardt M, Festen C, Van Oosterhout M, et al. NHG-Standaard Het PreventieConsult module Cardiometabool Risico. Huisarts Wet. 2011;54:138-55.

11. Robson J, Dostal I, Sheikh A, Eldridge S, Madurasinghe V, Griffiths C, et al. The NHS Health Check in England: an evaluation of the first 4 years. BMJ Open. 2016;6:e008840. [cited 2016 Mar 28]. Available from: http://www.ncbi. nlm.nih.gov/pmc/articles/PMC4735215/

12. Lawson KD, Fenwick E a L, ACH P, Pell JP. Comparison of mass and targeted screening strategies for cardiovascular risk: simulation of the effectiveness, cost-effectiveness and coverage using a cross-sectional survey of 3921 people. Heart Br Card Soc. 2010;96:208-12.

13. Pedersen CB. The Danish civil registration system. Scand J Public Health 2011;39:22-5.

14. Kass GV. An exploratory technique for investigating large quantities of categorical data. J R Stat Soc Ser C Appl Stat. 1980;29:119-27.

15. Shrier I, Platt RW. Reducing bias through directed acyclic graphs. BMC Med Res Methodol. 2008:8:70.

16. Andersen RM. Revisiting the behavioral model and access to medical care: does it matter? J Health Soc Behav. 1995:36:1-10.

17. Thygesen LC, Daasnes C, Thaulow I, Brønnum-Hansen H. Introduction to Danish (nationwide) registers on health and social issues: structure, access, legislation, and archiving. Scand J Public Health. 2011;39:12-6.

18. Andersen JS, Olivarius NDF, Krasnik A. The Danish National Health Service Register. Scand J Public Health. 2011;39:34-7.

19. Petersson F, Baadsgaard M, Thygesen LC. Danish registers on personal labour market affiliation. Scand J Public Health. 2011;39:95-8.

20. Baadsgaard M, Quitzau J. Danish registers on personal income and transfer payments. Scand J Public Health. 2011;39:103-5.

21. Jensen VM, Rasmussen AW. Danish education registers. Scand J Public Health. 2011;39:91-4

22. Pottegård A, Schmidt SAJ, Wallach-Kildemoes H, Sørensen HT, Hallas J, Schmidt M. Data resource profile: the Danish National Prescription Registry. Int J Epidemiol. 2017:46(3):798-798f

23. International Standard Classification of Education, ICSED 2011. UNESCO Institute for statistics; 2012. p. 1-88. Available from: http://www.uis.unesco.org. Accessed 30 Apr 2018

24. What are the equivalence scales. OECD Project on Income Distribution and Poverty; Available from: http://www.oecd.org/els/soc/OECD-NoteEquivalenceScales.pdf. Accessed 30 Apr 2018.

25. Jørgensen JT, Andersen JS, Tjønneland A, Andersen ZJ. Determinants of frequent attendance in Danish general practice: a cohort-based cross-sectional study. BMC Fam Pract. 2016;17:9.

26. Vedsted $\mathrm{P}$, Christensen MB. Frequent attenders in general practice care: a literature review with special reference to methodological considerations. Public Health. 2005;119:118-37.

27. Bender AM, Kawachi I, Jørgensen T, Pisinger C. Neighborhood deprivation is strongly associated with participation in a population-based health check. PLoS One. 2015;10:e0129819.

28. Groenenberg I, Crone MR, van Dijk S, Ben Meftah J, Middelkoop BJC, Assendelft WJJ, et al. Response and participation of underserved populations after a three-step invitation strategy for a cardiometabolic health check. BMC Public Health. 2015;15:854.

29. Bjerregaard A-L, Maindal HT, Bruun NH, Sandbæk A. Patterns of attendance to health checks in a municipality setting: the Danish 'Check Your Health Preventive Program'. Prev Med Rep. 2017:5:175-82.

30. Yancey AK, Ortega AN, Kumanyika SK. Effective recruitment and retention of minority research participants. Annu Rev Public Health. 2006;27:1-28.

31. Ahlmark N, Algren MH, Holmberg T, Norredam ML, Nielsen SS, Blom AB, et al. Survey nonresponse among ethnic minorities in a national health survey - a mixed-method study of participation, barriers, and potentials. Ethn Health. 2015:20:611-32.

32. Harkins C, Shaw R, Gillies M, Sloan H, Macintyre K, Scoular A, et al. Overcoming barriers to engaging socio-economically disadvantaged populations in CHD primary prevention: a qualitative study. BMC Public Health. 2010;10:391.

33. Groenenberg I, Crone MR, van Dijk S, Ben Meftah J, Middelkoop BJC, Assendelft WJJ, et al. Determinants of participation in a cardiometabolic health check among underserved groups. Prev Med Rep. 2016;4:33-43.

34. Tiessen AH, Smit AJ, Zevenhuizen S, Spithoven EM, der Meer KV. Cardiovascular screening in general practice in a low SES area. BMC Fam Pract. 2012;13:117. 
35. Gruber JS, Arnold BF, Reygadas F, Hubbard AE, Colford JM. Estimation of treatment efficacy with Complier Average Causal Effects (CACE) in a randomized stepped wedge trial. Am J Epidemiol. 2014;179:1134-42.

36. Fenger-Grøn M, Sig Ager Jensen M, Gram Junge A, Thomsen JL. Evaluering af ydelsen for aftalt forebyggelseskonsultation (0106ydelsen) i almen praksis De praktiserende lægers og patienters brug af samt oplevelser og erfaringer med den aftalte forebyggelseskonsultation. Århus: Afdelingen for Almen Medicin, Institut for Folkesundhed, Aarhus Universitet; 2008.

Ready to submit your research? Choose BMC and benefit from:

- fast, convenient online submission

- thorough peer review by experienced researchers in your field

- rapid publication on acceptance

- support for research data, including large and complex data types

- gold Open Access which fosters wider collaboration and increased citations

- maximum visibility for your research: over $100 \mathrm{M}$ website views per year

At BMC, research is always in progress.

Learn more biomedcentral.com/submissions 